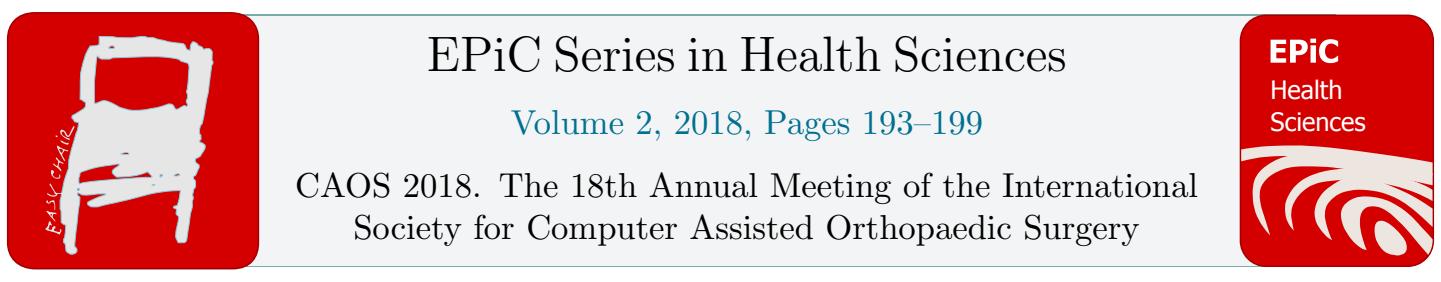

\title{
Proximal femoral osteochondroma excision aided by computer navigation: surgical technique and case series
}

\author{
Yang Sun $\mathrm{PhD}^{1}$, Chungming Chan $\mathrm{MD}^{2}$, Xiaohui Niu $\mathrm{MD}^{1 *}$ \\ 1,* Department of Orthopedic Oncology Surgery, Beijing Ji Shui Tan Hospital, \\ No. 31 Xin jie kou Dong Jie, Xi Cheng District. Beijing 100035, China \\ E-Mail: niuxiaohui@263.net \\ ${ }^{2}$ National University Hospital, Singapore, SINGAPORE
}

\section{INTRODUCTION}

Osteochondromata are common benign bone tumors that occur as solitary tumors as well as in the setting of multiple hereditary exostoses (MHE). The majority of patients do not suffer sufficient symptoms to warrant surgery, and it is well documented that spontaneous regression can occur[1]. Surgical removal is reserved for patients who suffer from significant symptoms or in whom malignant transformation[2,3] is suspected. Osteochondromata at the proximal femur can frequently be symptomatic and may present with pain[4,5], impingement[6], and sciatica secondary to nerve compression[7,8]. Osteochondromata at the proximal femur can also result in abnormal proximal femoral development and result in deformities such as coxa valga and acetabular dysplasia[9,10]. Resection of osteochondromata of the proximal femur is unique from resections at other anatomic sites because of 1) the close proximity of vital structures to the tumor and challenges in obtaining adequate exposure, 2) the high stress and high load that the femoral neck is subjected to and 3) the frequent need for prophylactic fixation owing to the potential for affecting the structural integrity with resection. In this article, we present a technique for using computer navigation as an aid to resection of proximal femoral osteochondromata to achieve the dual goals of adequate tumor removal and preservation of native bone stock, and results of a series of patients who underwent this procedure. 


\section{MATERIALS AND METHODS}

We identified patients in our institution's prospectively collected musculoskeletal oncology database who underwent computer-navigation aided resection of proximal femoral osteochondromata from February 2012 to August 2014. Approval for this study was obtained from the institutional review board, patients gave informed consent prior to study inclusion and hospital records for these patients were reviewed. Over the 30 month period, we identified seven eligible patients with a minimum of 6 months of follow-up. The mean age of these seven patients was 25.4 years (Range: 18-38 years) and the group comprised three males and four females. Mean follow-up was 13.1 months (Range: 7 - 27 months). Pre-operative workup included radiographs and computed tomography. Patients were followed up at 3,6, 12,18 , and 24 months with radiographic imaging as well as assessment of their functional outcomes using the Musculoskeletal Tumor Society (MSTS) score[11].

\section{RESULTS}

The presenting symptoms were pain and impingement in all of the patients, with one of the patients also having sciatica (Table 1). Five of the patients presented with isolated exostoses, while two of the seven patients had MHE.

A posterolateral approach was employed for the three patients with tumors projecting posteriorly or posteromedially (Figure 1), while an anterior (Smith-Petersen) approach was used for the four patients with anteriorly and medially based tumors. Prophylactic fixation was performed in four patients; a sliding hip screw was applied in three and intramedullary nailing in one. In these patients, an anterior approach was performed to access the tumor, and a separate lateral incision was used for the plating and nailing. The mean duration of surgery was 196 minutes (Range: 120-285 minutes)

No intra-operative fractures occurred, no complications occurred, and no unplanned secondary procedures were required in this study. All patients were satisfied with the results of the surgery with the mean MSTS scores at last follow up being 28.8 (Range: 27-30).

Table 1. Patient characteristics

\begin{tabular}{|c|c|c|c|c|c|c|c|c|c|c|c|}
\hline $\begin{array}{c}\text { Cas } \\
\mathrm{e}\end{array}$ & $\begin{array}{c}\text { Ag } \\
\mathrm{e}\end{array}$ & $\begin{array}{c}\text { Se } \\
\mathrm{x}\end{array}$ & $\begin{array}{c}\text { Sid } \\
\mathrm{e}\end{array}$ & $\begin{array}{c}\text { MHE } \\
?\end{array}$ & \multicolumn{2}{|c|}{ Site of tumor } & Approach & $\begin{array}{c}\text { Proph } \\
\text { ylactic } \\
\text { fixatio } \\
\mathrm{n}\end{array}$ & $\begin{array}{c}\text { Complica } \\
\text { tions }\end{array}$ & $\begin{array}{c}\text { Follow- } \\
\text { up (as } \\
\text { of } \\
\text { March } \\
2015)\end{array}$ & $\begin{array}{c}\text { MST } \\
\mathrm{S} \\
\text { scor } \\
\mathrm{e}\end{array}$ \\
\hline 1 & 38 & M & L & No & $\begin{array}{c}\text { Posterome } \\
\text { dial }\end{array}$ & $\begin{array}{c}\text { Femoral } \\
\text { neck }\end{array}$ & Posterolateral & None & None & 27 & 30 \\
\hline 2 & 25 & F & L & No & Medial & $\begin{array}{c}\text { Subtroc } \\
\text { h }\end{array}$ & Anterior & Nail & None & 17 & 27 \\
\hline 3 & 29 & M & L & No & $\begin{array}{c}\text { Posterome } \\
\text { dial }\end{array}$ & $\begin{array}{c}\text { Femoral } \\
\text { neck }\end{array}$ & Posterolateral & None & None & 12 & 28 \\
\hline
\end{tabular}


Proximal femoral osteochondroma excision aided by computer navigation: surgical ... $\quad$ Y. Sun et al.

\begin{tabular}{|c|c|c|c|c|c|c|c|c|c|c|c|}
\hline 4 & 25 & F & L & No & Posterior & $\begin{array}{c}\text { Femoral } \\
\text { neck }\end{array}$ & Posterolateral & None & None & 12 & 30 \\
\hline 5 & 18 & M & L & Yes & $\begin{array}{c}\text { Anteromed } \\
\text { ial }\end{array}$ & $\begin{array}{c}\text { Intertroc } \\
\text { hanteric } \\
\text { (IT) }\end{array}$ & Anterior & DHS & None & 9 & 28 \\
\hline 6 & 19 & F & R & No & Medial & $\begin{array}{c}\text { Femoral } \\
\text { neck/IT }\end{array}$ & Anterior & DHS & None & 8 & 30 \\
\hline 7 & 24 & F & L & Yes & Anterior & $\begin{array}{c}\text { Femoral } \\
\text { neck /IT }\end{array}$ & Anterior & DHS & None & 7 & 27 \\
\hline
\end{tabular}


Figure 1.

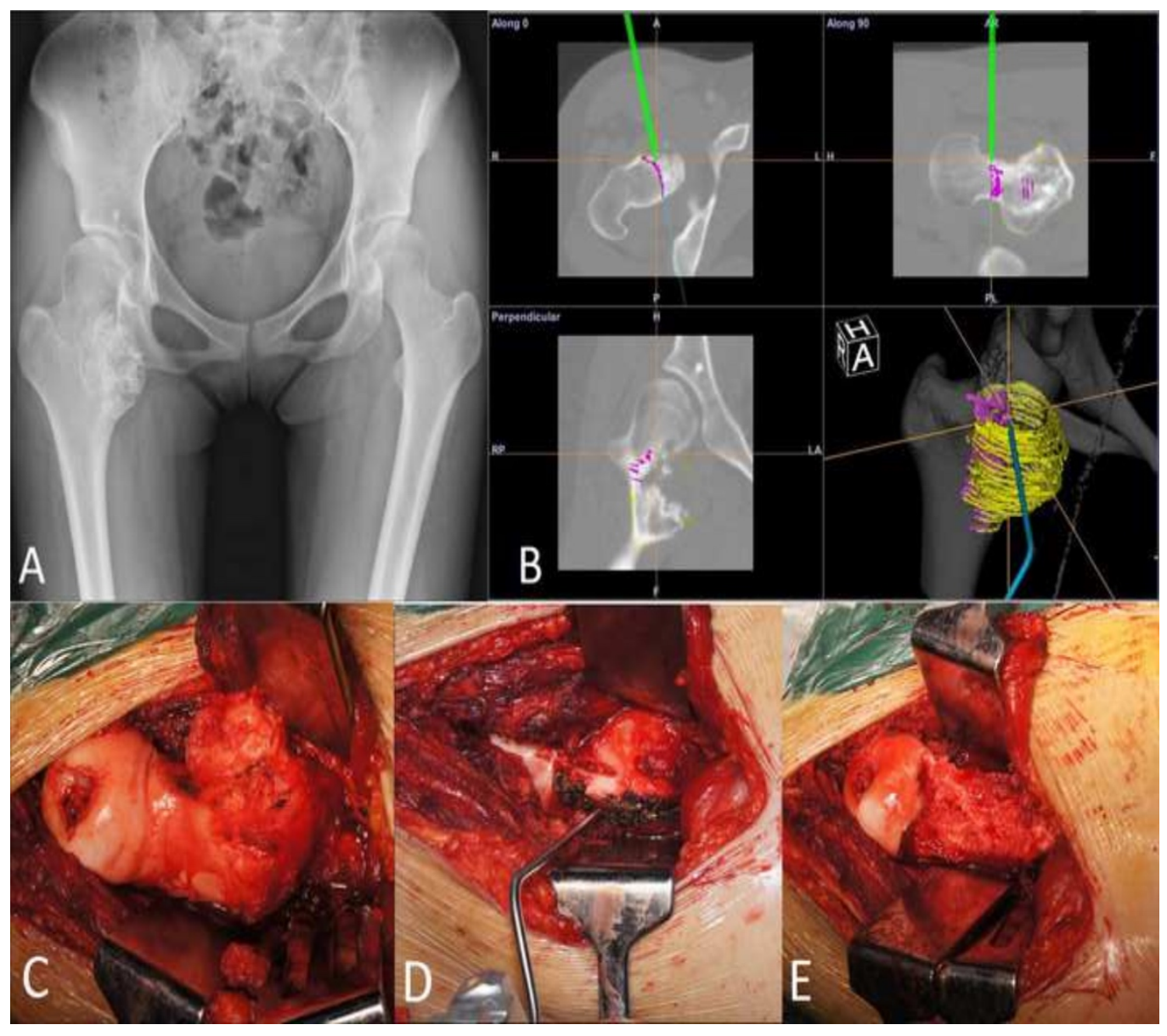

A: AP Pelvis xray, B: Computer screenshot during intra-operative navigation depicting axial CT image, coronal and sagittal reconstructions. Pre-operative plan for osteotomy marked in magenta, Green line depicting navigation stylus, Yellow circles depicting extent of tumor as plotted preoperatively.C: Exposure via a posterolateral approach D: Osteotomy plane marked using stylus. E: Femoral neck following tumor resection 


\section{DISCUSSION}

The proximal femur is a challenging location from which to resect osteochondromata and other tumors. Obtaining adequate exposure is of paramount importance, and different authors have described the use of a variety of approaches to provide surgical access to this area. These include the anterior (Smith-Petersen) approach[12], the posterolateral approach[4,6,7] the digastric approach[13] with accompanying hip dislocation, and the medial Ludloff approach[14]. Apart from permitting tumor visualization to facilitate removal, adequate exposure is essential to allow the surgeon to minimize unnecessary surgical trauma to this structurally important location. The biomechanical importance of the medial proximal femur[15] cannot be overstated, and femoral neck fractures[12,16] are a well described complication of resection of osteochondromata at this location. In our study, the patients underwent either an anterior or posterolateral surgical approach to expose the tumors depending on the location of the base of the tumor and the direction to which it projected. While the use of computer aided navigation cannot substitute for adequate exposure or pre-operative planning, it serves as an additional way of confirming the appropriate axes for performing osteotomies for the tumor resection.

In the last decade, computer aided navigation has gained traction as a valuable tool in the field of orthopaedic oncology[17]. The advantages of this technology are that it provides additional confirmation when operating in relatively poorly accessible anatomical sites, guides the performance of complex 3-dimensional osteotomies, and facilitates precision in performing osteotomies[18]. Precision in the field of oncology is required to achieve the concurrent objectives of obtaining satisfactory surgical margins and preserving vital bony structures such as articular surfaces. The use of computer aided navigation in this study helped minimize the excessive removal of vital bone around the medial femoral neck, and guided the osteotomies where the tumors had resulted in significant anatomic distortion and left the surgeon with few anatomic landmarks. In the two patients with tumors located in the femoral neck without involvement of the calcar femorale, it was felt that the precision afforded by navigation allowed the excision to be performed while limiting the amount of bone removed and avoiding the need for prophylactic fixation. In approaching medially based tumors, while the anterior approach does not provide as ample an exposure as the digastric approach nor as direct an exposure as a Ludloff approach, utilizing the navigation system permitted the performance of accurate osteotomies through this approach that is familiar to all orthopaedic surgeons. 
Computer modelling of femoroacetabular impingement (FAI)[19] has been described for pre-operative planning of osteoplasty in patients with FAI as a means of modelling hip movements and dynamic impingement. In that study, by taking into account dynamic factors and impingement arising from both femur and acetabulum, the authors predicted hip range of motion after osteoplasty accurately. The workflow in our study (described above) is predicated on the premise that restoring the normal anatomy of the proximal femur would address the patient's functional symptoms caused by pain from bony impingement. While not as comprehensive a means of planning resection as computer modelling, our technique utilizes a commercially available navigation system without requiring custom modifications.

In conclusion, our case series describes a novel application of computer aided navigation to aid in the resection of osteochondroma of the proximal femur with favorable outcomes in a small series of patients. When applied appropriately it can help the surgeon to achieve the goals of adequate tumor removal to address the mass effect, mechanical symptoms, or impingement while minimizing the removal of structurally important bone.

\section{REFERENCES}

1. Passanise AM, Mehlman CT, Wall EJ, Dieterle JP. Radiographic evidence of regression of a solitary osteochondroma: a report of 4 cases and a literature review. J Pediatr Orthop. 201;31:312-6.

2. Ahmed AR, Tan TS, Unni KK, Collins MS, Wenger DE, Sim FH. Secondary chondrosarcoma in osteochondroma: report of 107 patients. Clin Orthop Relat Res. 2003;411: 193-206.

3. Staals EL, Bacchini P, Mercuri M, Bertoni F. Dedifferentiated chondrosarcomas arising in preexisting osteochondromas. J Bone Joint Surg Am. 2007;89:987-93.

4. Kanauchi T, Suganuma J, Kawasaki T, Mochizuki R, Inoue Y, Uchikawa S, Kitamura K, Honda A. Fracture of an osteochondroma of the femoral neck caused by impingement against the ischium. Orthopedics. 2012;35:e1438-41.

5. Muzaffar N, Bashir N, Baba A, Ahmad A, Ahmad N. Isolated osteochondroma of the femoral neck presenting as hip and leg pain. A case study. Ortop Traumatol Rehabil. 2012;14:183-7

6. Hussain W, Avedian R, Terry M, Peabody T. Solitary osteochondroma of the proximal femur and femoral acetabular impingement. Orthopedics. 2010;33:51

7. Yu K, Meehan JP, Fritz A, Jamali AA. Osteochondroma of the femoral neck: a rare cause of sciatic nerve compression. Orthopedics. 2010;33.

8. Turan Ilica A, Yasar E, Tuba Sanal H, Duran C, Guvenc I. Sciatic nerve compression due to femoral neck osteochondroma: MDCT and MR findings. Clin Rheumatol. 2008; 27:403-404

9. Felix NA, Mazur JM, Loveless EA. Acetabular dysplasia associated with hereditary multiple exostoses: a case report. J Bone Joint Surg (Br) 2000;82- 
B:555-7.

10. Makhdom AM, Jiang F, Hamdy RC, Benaroch TE, Lavigne M, Saran N. Hip joint osteochondroma: systematic review of the literature and report of three further cases. Adv Orthop. 2014;2014:180254. Epub 2014 May 20.

11. Enneking WF, Dunham W, Gebhardt MC, Malawar M, Pritchard DJ, (1993) A System for the Functional Evaluation of Reconstructive Procedures After Surgical Treatment of Tumors of the Musculoskeletal System. Clin Orthop Relat Res, 286: p. 241-6

12. Ramos-Pascua LR, Sánchez-Herráez S, Alonso-Barrio JA, Alonso-León A. Solitary proximal end of femur osteochondroma. An indication and result of the en bloc resection without hip luxation. Rev Esp Cir Ortop Traumatol. 2012;56:24-31

13. Li M, Luettringhaus T, Walker KR, Cole PA. Operative treatment of femoral neck osteochondroma through a digastric approach in a pediatric patient: a case report and review of the literature. J Pediatr Orthop B. 2012;21:230-4

14. Francisco Chana-Rodríguez, David López-Capapé, José Rojo-Manaute, Javier Vaquero-Martín, Juan Manuel Alonso-Martín, Manuela González-Santander, Manuel Villanueva-Martínez. Ludloff approach for osteochondroma in the lesser trochanter in a young middle-distance runner. European Orthopaedics and Traumatology 2011;2: 83-85

15. Stiehl JB, Jacobson D, Carrera G. Morphological analysis of the proximal femur using quantitative computed tomography. Int Orthop. 2007;31:287-92.

16. Bottner F, Rodl R, Kordish I, Winklemann W, Gosheger G, Lindner N. Surgical treatment of symptomatic osteochondroma. A three- to eight-year follow-up study. J Bone Joint Surg Br 2003; 85:1161-1165

17. Wong KC, Kumta SM. Use of Computer Navigation in Orthopedic Oncology. Curr Surg Rep. 2014;2:4

18. Ritacco LE, Milano FE, Farfalli GL, Ayerza MA, Muscolo DL, Aponte-Tinao LA. Accuracy of 3-D planning and navigation in bone tumor resection. Orthopedics. 2013;36:e942-50

19. Bedi A, Dolan M, Magennis E, Lipman J, Buly R, Kelly BT. Computer-assisted modeling of osseous impingement and resection in femoroacetabular impingement. Arthroscopy. 2012;28:204-10

\section{DISCLOSURES}

The authors declare that they have no conflict of interest. No financial or material support was received in relation to this study. None of the authors has any commercial or proprietary or financial interest in any device, or equipment mentioned in the article. 